\title{
Correction to: An optimal method for searching failure surfaces of hard thin-layered anaclinal rock slopes with cross joints
}

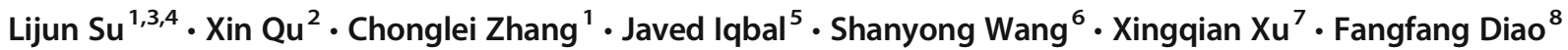 \\ Published online: 24 August 2021 \\ (C) Saudi Society for Geosciences 2021
}

\section{Arabian Journal of Geosciences (2021) 14:1422 \\ https://doi.org/10.1007/s12517-021-07814-9}

The original version of this paper was published with error. The responsible editor's name "Zeynal Abiddin Erguler" was inadvertently captured as article sub-title. Given in this article is the corrected title.

The original article has been corrected.

The online version of the original article can be found at https://doi.org/ 10.1007/s12517-021-07814-9

Xin Qu

xqu1987@163.com

1 Key Laboratory of Mountain Hazards and Earth Surface Processes, Institute of Mountain Hazards and Environment, Chinese Academy of Sciences, Chengdu 610041, China

2 School of Civil and Architecture Engineering, Anyang Institute of Technology, West Section Huanghe Road, Anyang 455000, Henan, Province, People's Republic of China

3 CAS Center for Excellence in Tibetan Plateau Earth Sciences, Beijing 100101, China
4 University of Chinese Academy of Sciences, Beijing 100049, China

5 School of Civil and Environmental Engineering, National University of Sciences and Technology (NUST), Islamabad, Pakistan

6 Department of Civil Engineering, The University of Newcastle, Newcastle, NSW, Australia

7 College of Water Conservancy, Yunnan Agricultural University, Kunming 650201, China

8 School of Foreign Languages, Anyang Institute of Technology, Anyang 455000, China 